\title{
Spatiotemporal Dynamics of Brain-Derived Neurotrophic Factor mRNA Induction in the Vestibulo-Olivary Network during Vestibular Compensation
}

\author{
Yue Xin Li, ${ }^{1}$ Takanori Hashimoto,, ${ }^{1}$ Wataru Tokuyama, ${ }^{2}$ Yasushi Miyashita, ${ }^{1,2,3}$ and Hiroyuki Okuno ${ }^{2}$ \\ ${ }^{1}$ Mind Articulation Project, International Cooperative Research Project, Japan Science and Technology Corporation, \\ Yushima, Tokyo 113-0034, Japan, 2Department of Physiology, University of Tokyo School of Medicine, Hongo, Tokyo \\ 113-0033, Japan, and ${ }^{3}$ National Institute for Physiological Sciences, Myodaiji, Okazaki 444-8585, Japan
}

\begin{abstract}
Vestibular compensation, which is the behavioral recovery from vestibular dysfunction produced by unilateral labyrinthectomy $(\mathrm{UL})$, is attributed to functional and structural reorganization of neural networks in the central vestibular system. To assess the possible contribution of brain-derived neurotrophic factor (BDNF) to this recovery process, we investigated changes in mRNA expression levels in the central vestibular system after UL. We evaluated BDNF mRNA expression levels by quantitative reverse transcription-PCR and in situ hybridization. We found that BDNF mRNA is differentially induced in the medial vestibular nucleus ipsilateral to UL and in the prepositus hypoglossi and inferior olive on the contralateral side. The BDNF mRNA induction lasted for at least $24 \mathrm{hr}$ and returned to the basal expression level within $72 \mathrm{hr}$ after UL. In contrast to BDNF mRNA induction, the expression of an immediate-early gene,
\end{abstract}

c-fos, quickly reached the maximum level at $3 \mathrm{hr}$ and decreased to the basal level within $24 \mathrm{hr}$ after UL. Neither BDNF or c-fos induction was observed in sham-operated animals. The persistent induction of BDNF after UL temporally corresponded to early behavioral manifestations of vestibular compensation. We further found that trkB mRNA was expressed in the central vestibular network at high levels, although its expression levels did not change over time after UL. Because BDNF is implicated in regulating synaptic structure and function, these results provide support for the hypothesis that BDNF is involved in neuronal reorganization that allows vestibular compensation.

Key words: vestibular compensation; labyrinthectomy; lesioninduced plasticity; brain-derived neurotrophic factor; trkB; quantitative RT-PCR
The CNS has the capacity to adapt to peripheral lesions through plastic changes that eventually lead to the restitution of normal function. Unilateral labyrinthectomy (UL) induces a characteristic syndrome of ocular motor and postural disorders (Precht, 1979; Ito, 1984). Many of these symptoms disappear over time in a process called vestibular compensation; postural and spontaneous oculomotor symptoms mostly disappear in several days in the early phase of vestibular compensation, whereas some residual symptoms gradually disappear over the ensuing weeks or months (Darlington et al., 1991; Dieringer, 1995). Because UL results in a permanent loss of vestibular inputs from the lesioned side, the compensatory process is assumed to be attributable to the reorganization of the neural network in the central vestibular system (Galiana et al., 1984; Ris et al., 1995). Many brain regions, such as the medial vestibular nucleus (MVN) and inferior olivary complex, are implicated in this process (Kaufman et al., 1992; Cirelli et al., 1996; Balaban and Romero, 1998). However, to date, the molecular mechanisms underlying this process remain unknown.

Neurotrophins are characterized by their ability to regulate neuronal survival and differentiation during development.

Received Oct. 11, 2000; revised Jan. 17, 2001; accepted Jan. 24, 2001.

This work was supported in part by Grant-in-Aid 07102006 for Specially Promoted Research to Y.M. and by Grant-in-Aid 11780574 for Encouragement of Young Scientists to H.O. from the Japanese Ministry of Education, Science, Sports, and Culture. We thank Dr. S. Nagao for helpful advice on measurement of eye movement.

Correspondence should be addressed to Hiroyuki Okuno, Department of Physiology, University of Tokyo School of Medicine, 7-3-1 Hongo, Bunkyo-ku, Tokyo 113-0033, Japan. E-mail: okuno@m.u-tokyo.ac.jp.

Copyright (C) 2001 Society for Neuroscience $0270-6474 / 01 / 212738-11 \$ 15.00 / 0$
Among these, brain-derived neurotrophic factor (BDNF) has been associated with the development of the vestibular system. Deletion of the BDNF gene causes a severe loss of vestibular neurons in mice (Jones et al., 1994; Ernfors et al., 1995; Bianchi et al., 1996). In addition to its function in development, it has been proposed that BDNF regulates broader aspects of neuronal function, including axonal and dendritic morphology, the efficiency of synaptic transmission, and the pattern and stability of synaptic contacts, even in adulthood (Hanover et al., 1999; Horch et al., 1999; Kafitz et al., 1999). Thus, BDNF might be involved in the reorganization of neural circuits in the central vestibular system during vestibular compensation, and if so, it is likely that $\mathrm{BDNF}$ is induced in areas of the brain that participate in the compensatory process after UL. However, there has been no quantitative and systematic study on BDNF induction in the central vestibular system after UL. Such information is crucial for linking BDNF induction with the behavioral compensatory process and is required to characterize BDNF function during vestibular compensation.

In the present study, to quantitatively determine BDNF mRNA levels in small regions of the brain, we applied a quantitative reverse transcription (RT)-PCR method, through which a gene of interest was coamplified with an internal standard gene in a single reaction tube (Gause and Adamovicz, 1995). In this method, measurement of the amount of target product relative to the internal standard cancels out variations associated with PCR amplification between individual reactions (Okuno et al., 1999; Tokuyama et al., 1999, 2000). We found the spatiotemporalspecific induction of BDNF mRNA in the central vestibular 
network after UL. The induction of BDNF mRNA was more persistent than that of an inducible transcription factor gene, c-fos, and the time course of the BDNF induction closely corresponded to early behavioral manifestations of vestibular compensation.

\section{MATERIALS AND METHODS}

Labyrinthectomy. Seven-week-old male Wister rats (200-230 gm; CLEA Japan Inc., Tokyo, Japan) were used for this study. All animal experiments were performed in accordance with the Guide for the Care and Use of Laboratory Animals and regulations of the University of Tokyo School of Medicine. UL was performed as described previously with modifications (Sato et al., 1997). Rats $(n=91)$ were anesthetized with a short-lasting anesthetic, propofol, by continuous infusion $\left(0.4 \mathrm{mg} \cdot \mathrm{kg}^{-1} \cdot \mathrm{min}^{-1}\right.$, i.v.) through the tail vein. Lidocaine was also administered locally. Using a surgical stereoscope, the auditory bulla was exposed unilaterally by a postauricular approach and was removed to expose the middle ear cavity. The oval window was opened and enlarged with a fine dental drill, and the utricle and saccule as well as the cristae of the semicircular canals were ablated by aspiration. In this study, the left labyrinth was severed for all animals; the left side was designated as the ipsilateral side and the right side as the contralateral side. For a control of confounded effects of anesthesia and unilateral soft tissue injury, rats $(n=36)$ were submitted to a sham operation under the same anesthesia; the left bulla was opened, but the otolith organs were spared. After suturing the postauricular incision, the infusion of the anesthetics was stopped. All animals recovered from anesthesia no later than $5 \mathrm{~min}$ after, and the labyrinthectomized animals immediately showed behavioral signs of UL: rolling and circling behavior, head tilt and neck deviation toward the lesioned side, and contralateral limb extension as well as horizontal spontaneous nystagmus (SN) (Fig. 1).

Tissue preparation. After the designated survival times (3, 6, 24, and 72 hr after UL), rats were anesthetized with ethyl ether and decapitated using a rodent guillotine. Brains were rapidly removed and frozen on powdered dry ice within $3 \mathrm{~min}$. The brains were cut coronally into $150-\mu \mathrm{m}$-thick sections with a cryostat. Each section was placed in a dish containing chilled PBS just before tissue dissection as described previously (Tokuyama et al., 1998, 1999). The tissue dissection was performed under a stereomicroscope on the basis of the borders in an atlas of the brainstem described by Paxinos et al. (1999). The tissues were carefully dissected to minimize contamination of other nuclei. The MVN and prepositus hypoglossi $(\mathrm{PrH})$ were excised from slices corresponding approximately to Figures $102-158$ of the atlas of Paxinos et al. (1.2-3.3 $\mathrm{mm}$ posterior from the interaural line). The inferior olive (IO) was excised from slices corresponding approximately to Figures 171-206 of the atlas (3.8-5.2 $\mathrm{mm}$ posterior from the interaural line). The excised tissues of the IO contained most of the medial region of the inferior olivary complex but did not contain the whole of the complex and were used because the medial region has been proposed to be especially important for vestibular compensation (Kaufman et al., 1992; Goto et al., 1997; Sato et al., 1997). The hypoglossal nucleus (XII) was also excised from slices corresponding approximately to Figures 171-213 of the atlas (3.8-5.4 $\mathrm{mm}$ posterior from the interaural line) as a control area.

All tissues were separately excised from the ipsilateral and contralateral sides to the lesion, collected, frozen immediately on dry ice, and stored at $-80^{\circ} \mathrm{C}$ until RNA extraction (Tokuyama et al., 1998). For each brain area, we pooled excised tissues from six animals to obtain sufficient tissue for mRNA quantification. The pooled tissues were processed using an RNA extraction kit (TOTALLY RNA; Ambion, Austin, TX) for isolation of total RNA as described previously (Tokuyama et al., 1999). The RNA preparation was repeated three times using independent animal groups, for each survival time. Unoperated rats $(n=18$ for mRNA quantification) were also used as control animals in this study.

Quantitative RT-PCR. Expression levels of mRNAs were quantified by using an RT-PCR coamplification method as described previously (Tokuyama et al., 1998, 1999, 2000; Okuno et al., 1999). Specific primers for PCR coamplification were designed based on the published sequences of rat BDNF (GenBank accession number M61175), trkB (GenBank accession number M55291), c-fos (GenBank accession number X06769), $\alpha$-tubulin (GenBank accession number V10227), and hypoxanthineguanine phosphoribosyltransferase (hprt) (GenBank accession number M63983) genes. The sequences of the primers were as follows: for BDNF, 5'-GTGACAGTATTAGCGAGTGGG-3' and 5'-GGGTAGTTCGGCATTGC-3'; for trkB, 5'-TGACGCAGTCGCAGATGCTG-3'
A

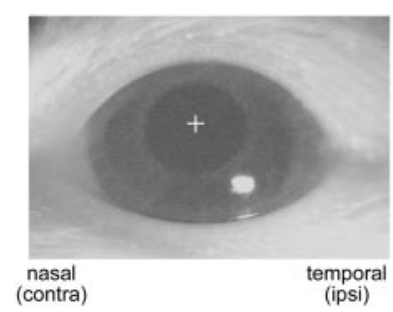

B

$8 \mathrm{~h}$

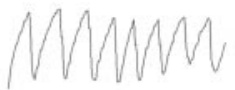

$24 \mathrm{~h}$

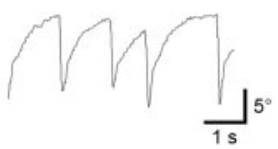

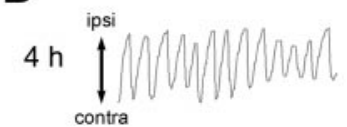

C

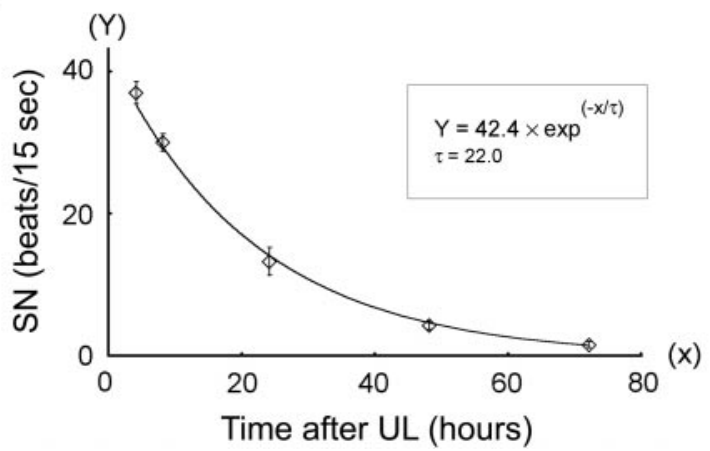

Figure 1. Measurement of SN after UL as an index of vestibular compensation. $A$, View of the rat eye on a computer monitor. The left eye of a labyrinthectomized rat was illuminated by infrared light, and its reflection was monitored through a CCD camera in darkness. The trajectory of the center of the pupil (indicated by the cross) was traced by a computeraided, position-analyzing system. $B$, Representative traces of eye movements at 4, 8, and $24 \mathrm{hr}$ after UL. The frequency of the quick phase of SN, which was a rapid, large-amplitude eye movement contralateral to the lesion side, was measured and plotted in $C$. $C$, Time course of disappearance of SN frequency after UL. Each data point represents the mean number of SN quick-phase movements in $15 \mathrm{sec}$ across seven animals. The solid line represents a single exponential function with a time constant $(\tau)$ of $22.0 \mathrm{hr}$ fitted by least-squares regression $\left(R^{2}=0.998\right)$. Error bars represent SEM.

and 5'-TTTCCTGTACATGATGCTCTCTGG-3'; for c-fos, 5'-GACCGAGATTGCCAATCTAC-3' and 5'-GGAAACAAGAAGTCATCAAAGG-3'; for $\alpha$-tubulin, 5'-ACCAGATGGTGAAATGTG- AC-3' and $5^{\prime}$-TCAGCATACACACAGCTCTC-3'; and for hprt, 5'-GCTGACCTGCTGGATTACATTA-3' and 5'-CCACTTTCGCTG- ATGACACAA- $3^{\prime}$. These primers amplify a $213 \mathrm{bp}$ fragment in the mature peptide coding region of the BDNF gene, a $245 \mathrm{bp}$ in the tyrosine kinase coding region of the trkB gene, 285 bp in the coding region just after the leucine zipper domain of the c-fos gene, and 237 and $410 \mathrm{bp}$ in the coding regions of the $\alpha$-tubulin and hprt genes, respectively. We have confirmed that all primer sets specifically amplified their corresponding genes; the primers for BDNF did not amplify other neurotrophins, the primers for trkB amplify neither splicing variants of the TrkB receptor nor the other Trk receptors, and the primers for c-fos did not amplify other fos-related genes.

The procedures of reverse transcription and PCR coamplification were essentially the same as described previously (Tokuyama et al., 1998; Okuno et al., 1999). In the present study, the hprt gene was used as an internal standard gene (Tokuyama et al., 1999). Each gene of interest (target gene) was amplified along with the hprt gene in the same reaction tube in the presence of $\left[\alpha^{-}{ }^{32} \mathrm{P}\right] \mathrm{dCTP}$. PCR was terminated in two consecutive PCR cycles (19 and 20 cycles for BDNF and c-fos; 17 and 18 cycles for trkB and $\alpha$-tubulin). The amplified PCR products were separated on $6 \%$ polyacrylamide gels, and the incorporated radioactivity was measured using phosphorimaging (BAS2000; Fujix, Tokyo, Japan). For each PCR cycle, incorporated radioactivity of the target gene fragment was divided by that of the internal standard gene fragment. The quantitative results were averaged between the two cycles and defined as mRNA expression levels. The mRNA expression levels in the ipsilateral and contralateral sides were treated as paired data. Statistical signifi- 
A

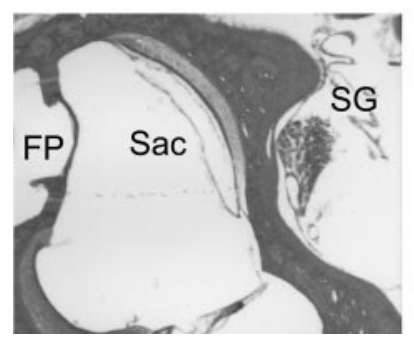

B

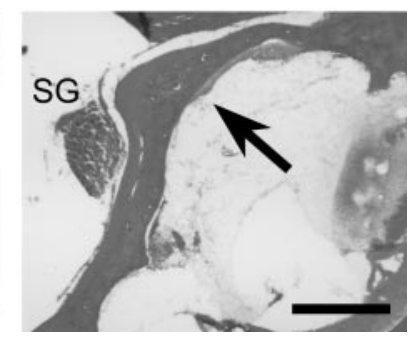

Figure 2. Histological verification of unilateral surgical labyrinthectomies. Representative horizontal sections of intact $(A)$ and lesioned $(B)$ sides of the otolith organs are shown. The rostral aspect of the sections is oriented upward, and the medial aspect is right in $A$ and left in $B$. The arrow indicates a damaged saccule $(\mathrm{Sac})$ in the lesioned side. Scarpa's ganglia $(S G)$ were left intact on both the intact and lesioned sides. FP, The foot plate of the stapes. Scale bar, $0.5 \mathrm{~mm}$.

cance was inferred from a mixed-model (split-plot) repeated-measures ANOVA [between-subjects factor, survival time; within-subjects factors, laterality (ipsilateral vs contralateral) and interaction between laterality and survival time] with post hoc analyses (Duncan's multiple comparison and the Student's paired $t$ test). Statistical analyses were performed using a standard statistical package (Statistical Analysis System; SAS Institute, Cary, NC).

Measurement of spontaneous nystagmus. Seven rats were used to characterize the time course of the decline in the frequency of horizontal spontaneous nystagmus after UL (Kitahara et al., 1995; Goto et al., 1997). The rats initially underwent an operation under pentobarbital anesthesia $(50 \mathrm{mg} / \mathrm{kg}$, i.m.) to build a platform for fixation of the head (Katoh et al., 1998). After $2 \mathrm{~d}$ recovery, the rats underwent UL as described above. At the designated sampling times (4, 8, 24, 48, and $72 \mathrm{hr}$ after UL), each rat was mounted on an apparatus for eye movement measurement, with its head fixed and its body loosely restrained in a plastic cylinder. The rat's head was tilted so that the horizontal (lateral) semicircular canals were positioned approximately parallel to the horizontal plane. Spontaneous nystagmus was recorded by using an infrared camera system in darkness (Katoh et al., 1998). The pupil of the left eye was illuminated by infrared light-emitting diodes (wavelength, $870 \mathrm{~nm}$; TLN227; Toshiba, Tokyo, Japan) and monitored by a charge-coupled device (CCD) camera (XC-75; Sony, Tokyo, Japan). The real-time position of the eye was measured by calculating the center of the left pupil using a position-analyzing system (Hasegawa et al., 1998) (Fig. 1A) and stored in a personal computer equipped with a PowerLab analogto-digital board system (ADInstruments, Castle Hill, Australia). The frequency of spontaneous nystagmus was measured as the number of quick phase beats toward the contralateral side relative to UL in $15 \mathrm{sec}$ (4-6 repeated measures per animal per sampling time) (Fig. 1C).

Histological verification of surgical labyrinthectomies. After removal of the brains, the temporal bones of randomly sampled UL animals were dissected from the skulls, fixed in $4 \%$ paraformaldehyde- $0.1 \mathrm{~m}$ phosphate buffer, $\mathrm{pH} 7.4$, for $3-5 \mathrm{~d}$, and decalcified in $1.3 \mathrm{~N} \mathrm{HCl}$ containing 5 mM EDTA for $5 \mathrm{~d}$. The decalcified tissues were then cryoprotected, frozen in the OTC compound (Miles Scientific Inc., Elkhart, IN), horizontally cut with a cryostat into $20-\mu \mathrm{m}$-thick sections, and thaw-mounted on slides. The sections were stained with hematoxylin and eosin to verify that the otolith organ maculae and semicircular canal cristae were damaged, whereas the facial nerve, cochlear nerve and Scarpa's ganglion were spared in the lesioned side (Fig. 2). During the removal of the brains, no damage to the flocculus, paraflocculus, and brainstem was also confirmed.

In situ hybridization. Rats ( $n=12$ for UL and $n=10$ for control) were decapitated, and brainstems were cut serially into $10 \mu \mathrm{m}$ coronal sections using a cryostat. Hybridization was performed essentially as described previously (Okuno et al., 1999; Hashimoto et al., 2000). Antisense and sense cRNA probes for BDNF (a $460 \mathrm{bp}$ probe) were synthesized using T7 and T3 RNA polymerase, respectively, in the presence of $\left[\alpha-{ }^{35}\right.$ S $]$ UTP. The brainstem sections were fixed in $4 \%$ paraformaldehyde, washed in PBS, acetylated in $0.1 \mathrm{M}$ triethanolamine- $-0.25 \%$ acetic anhydride, and incubated in a hybridization buffer without probes. The sections were then hybridized with the ${ }^{35}$ S-labeled cRNA probes $(1 \times$
$10^{7} \mathrm{cpm} / \mathrm{ml}$ ) and incubated at $58^{\circ} \mathrm{C}$ for $16 \mathrm{hr}$. The sections were washed in $2 \times \mathrm{SSC}-50 \%$ formamide at $58^{\circ} \mathrm{C}$, followed by RNase A treatment $(40$ $\mu \mathrm{g} / \mathrm{ml}$ ), and then washed in $1 \times \mathrm{SSC}-50 \%$ formamide at $58^{\circ} \mathrm{C}$ and rinsed in $0.5 \times \mathrm{SSC}$ at room temperature. After dehydration, the sections were dipped in Kodak (Eastman Kodak, Rochester, NY) NTB3 emulsion (diluted 1:1 with distilled water), exposed for 3 weeks at $4^{\circ} \mathrm{C}$, developed, fixed, and counterstained through the emulsion with cresyl violet.

\section{RESULTS \\ Vestibular compensation after unilateral labyrinthectomy}

In the present study, we used a total of 91 Wister rats that underwent UL by surgical disruption of the labyrinth while anesthetized with a short-lasting anesthetic, propofol. All of the animals rapidly recovered from this anesthesia no later than $5 \mathrm{~min}$ after the surgery and immediately showed behavioral signs of UL. To characterize the compensatory processes after UL, we first investigated the time course of disappearance of horizontal SN after UL as an index of development of vestibular compensation (Kitahara et al., 1995; Goto et al., 1997). We monitored eye movements of rats by an infrared CCD camera in darkness (Fig. $1 A$ ) and traced eye position at various time points after UL (Fig. $1 B)$. The mean SN frequency across seven animals showed a single exponential decay $\left(R^{2}=0.998\right)$ with a time constant of 22 hr and an initial SN frequency of 42 beats per $15 \mathrm{sec}$ (Fig. $1 C$ ). SN had virtually disappeared $72 \mathrm{hr}$ after UL under our experimental conditions. Other symptoms of UL, such as rolling and circling behavior, torsion of the head, and limb extension, also disappeared within $1 \mathrm{hr}$ to $3 \mathrm{~d}$ after UL, depending on the symptoms. These observations were consistent with previous reports that described SN frequency and other behavioral symptoms after UL in rats (Kitahara et al., 1995; Cirelli et al., 1996; Goto et al., 1997). These results indicate that the early stage of vestibular compensation develops by $\sim 3 \mathrm{~d}$ after UL in rats.

\section{Evaluation of mRNA expression levels by quantitative RT-PCR}

Previous electrophysiological and neurochemical studies have suggested that several brain regions participate in the compensatory process after UL (Smith and Curthoys, 1988; Cirelli et al., 1996; Goto et al., 1997). In particular, the mapping of immediateearly gene expression has consistently demonstrated the involvement of three specific subregions in the brainstem: the MVN (Kaufman et al., 1992; Kitahara et al., 1995; Darlington et al., 1996), the PrH (Kaufman et al., 1992; Kitahara et al., 1995; Cirelli et al., 1996), and the medial region of the IO (Kaufman et al., 1992; Kitahara et al., 1995; Cirelli et al., 1996; Sato et al., 1997). On the basis of this neurochemical evidence, we further investigated the molecular mechanisms that underlie vestibular compensation by focusing on changes in BDNF mRNA expression levels in these brainstem regions after UL. The three nuclei of interest and one control nucleus, the XII, were microdissected separately from the ipsilateral and contralateral sides toward the lesion and used for RNA extraction (Fig. $3 A$ ). We pooled the tissues excised from six animals to obtain sufficient amounts of tissue for each RNA sample. We prepared three independent RNA samples for each of the survival times of 3, 6, 24, and $72 \mathrm{hr}$ after UL.

We quantified mRNA expression levels by using a quantitative RT-PCR method, in which the gene of interest was coamplified with an internal standard gene in a single reaction tube (Gause and Adamovicz, 1995; Okuno et al., 1999; Tokuyama et al., 2000). The hprt gene was used as the internal standard (Tokuyama et al., 
A

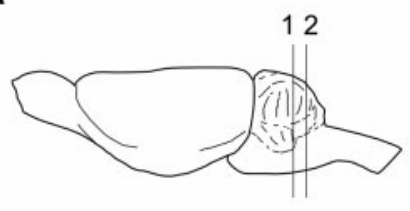

B

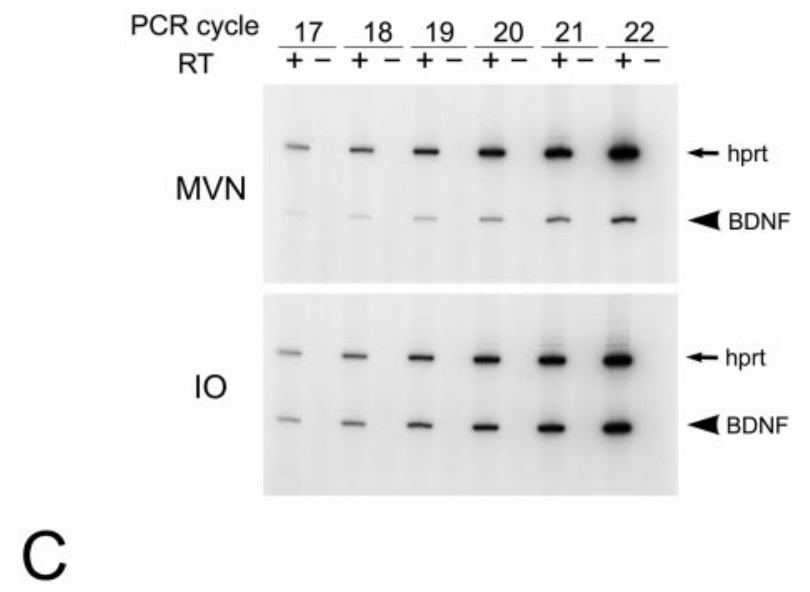

C

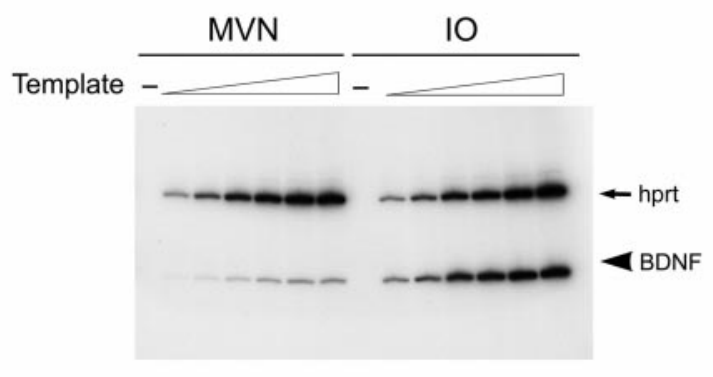

1

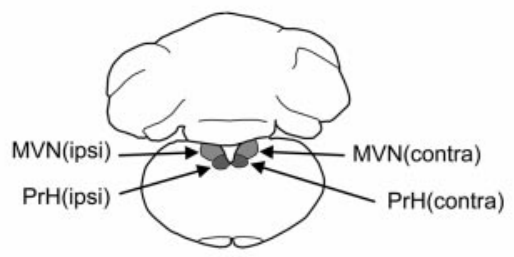

Lesion side Intact side
2

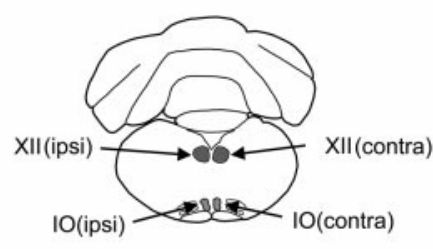

Lesion side Intact side
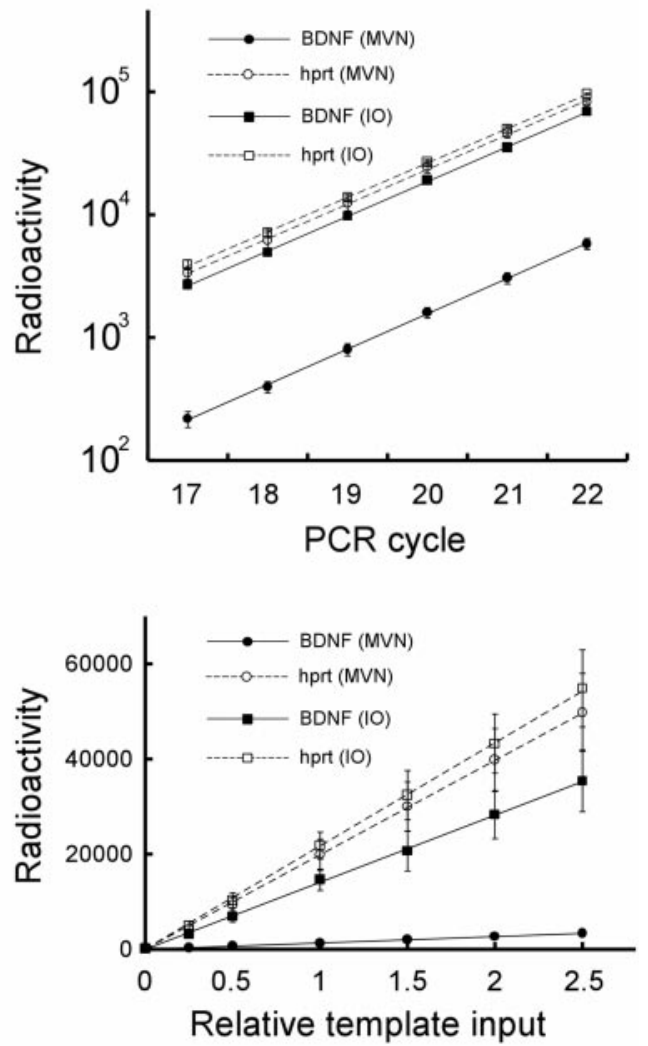

Figure 3. RT-PCR-based mRNA quantification in rat brainstem nuclei. $A$, Regions of interest for mRNA quantification. A lateral view of the rat brain is shown on the left, and coronal sections are indicated on the right. Each brainstem nucleus was separately microdissected from the ipsilateral (Lesion) and contralateral (Intact) sides toward UL and subjected to RNA quantification experiments. B, Kinetics of PCR coamplification of BDNF with the internal standard gene (hprt). Total RNAs from the MVN and IO were incubated with $(+)$ or without $(-)$ reverse transcriptase $(R T)$, followed by PCR coamplification. The left panels are representative gel patterns of MVN and IO samples. The radioactivity of PCR fragments of BDNF and hprt was measured and logarithmically plotted against the number of PCR cycles (mean $\pm \mathrm{SEM} ; n=4$ ) in the right panel. Lines represent exponential regressions for BDNF (solid lines) and hprt (broken lines). C, The linear relationship between the amount of template and amplified products. Various amounts of templates of RT products were amplified for 19 PCR cycles. The left panel shows a representative gel pattern of MVN and IO samples. The radioactivity of PCR fragments of BDNF and hprt was measured and plotted in a linear scale against the relative input amount of the template (mean \pm SEM; $n=$ 4 ) in the right panel. Lines represent linear regressions for BDNF (solid lines; $r=1.00$ for MVN; $r=0.99$ for IO) and hprt (broken lines; $r=1.00$ for both MVN and IO).

1999). Before the actual quantification experiments, we confirmed that PCR fragments were derived from reversetranscribed mRNAs and not from chromosomal DNA (Fig. 3B, left). We next confirmed that the target and internal standard genes were coamplified at the same efficiency during PCR (Fig. $3 B$, right). The amplification rates deduced from the slopes of the regression lines for BDNF and hprt were identical in each brain area $(\mathrm{MVN}, 1.95 \pm 0.07$ for BDNF vs $1.93 \pm 0.05$ for $h p r t$, paired $t$ test, $p>0.82$; IO, $1.92 \pm 0.02$ for BDNF vs $1.91 \pm 0.02$ for $h p r t$, $p>0.72$ ) and were very close to the theoretical rate of 2 , at least, up to 22 PCR cycles. We further confirmed that the amounts of amplified PCR fragments faithfully reflected input amounts of templates (Fig. $3 C$ ). For each gene in each brain area, radioactivity of the amplified PCR product perfectly correlated to the input amount of template $(r=0.99-1.00, p<0.001)$. These results indicate that mRNA expression levels were reliably measured under our RT-PCR conditions.

\section{BDNF mRNA induction after unilateral labyrinthectomy}

Using this RT-PCR quantification method, we determined the BDNF mRNA levels in the MVN, PrH, and IO after UL (Fig. 4). The BDNF mRNA levels changed differentially over time and laterality (i.e., ipsilateral and contralateral sides to the lesion) after UL, among the regions studied. 
A
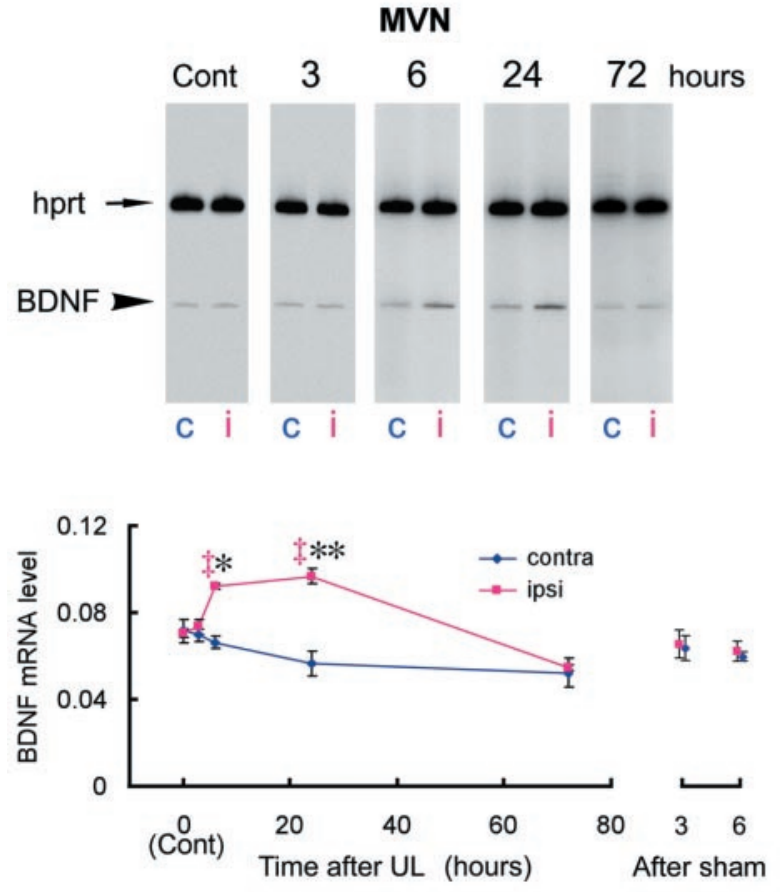

C
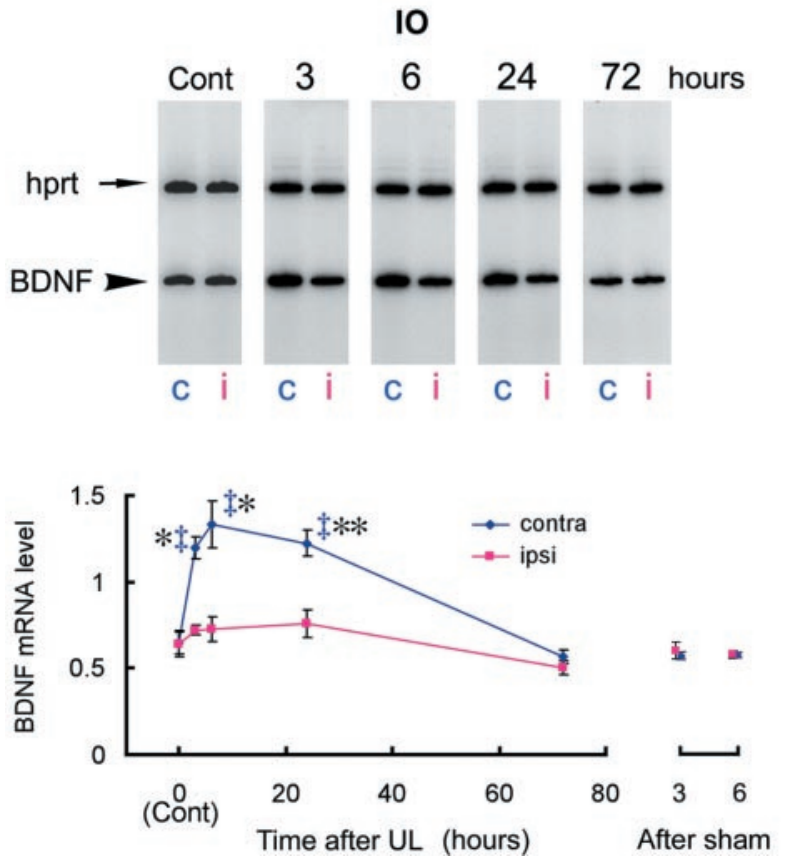

B
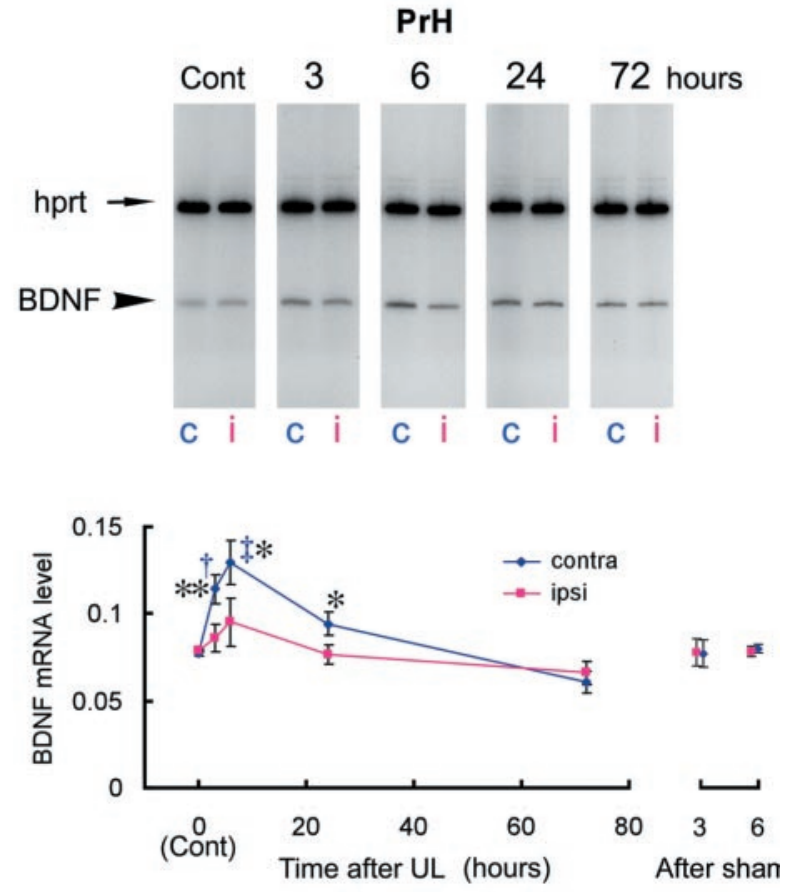

D
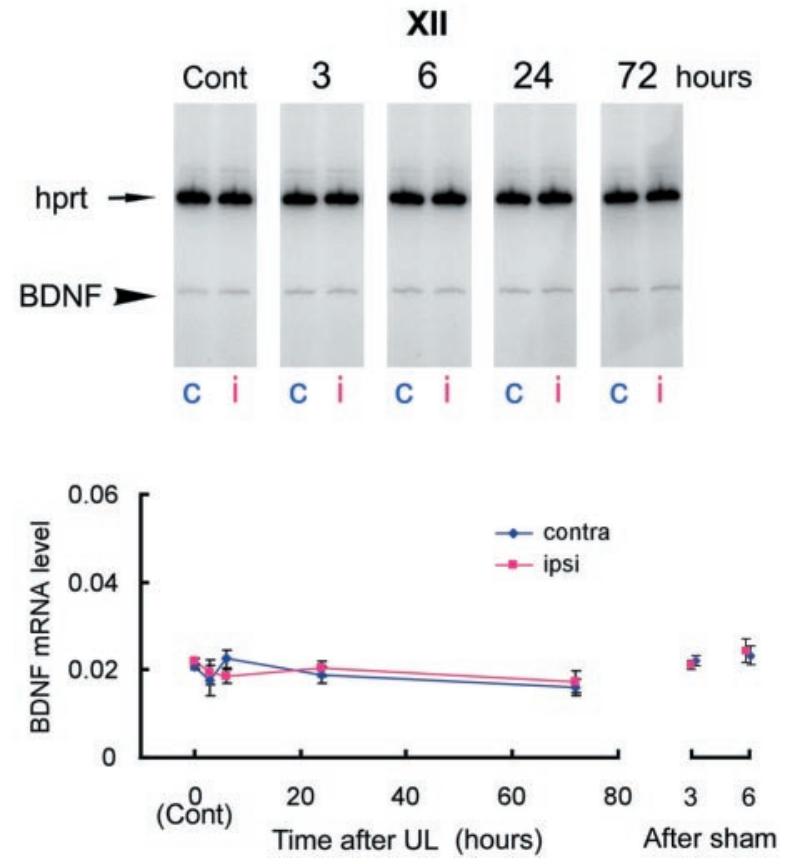

Figure 4. BDNF mRNA induction during the early phase of vestibular compensation. The BDNF mRNA expression levels were evaluated by RT-PCR coamplification in the MVN $(A), \operatorname{PrH}(B), \mathrm{IO}(C)$, and XII $(D)$, at 3, 6, 24, and $72 \mathrm{hr}$ after UL. The BDNF mRNA levels were defined as amounts of RT-PCR products of BDNF normalized by those of the internal standard hprt gene, which was coamplified with BDNF in the same reaction tube. Each data point in the graphs represents the mean of the BDNF mRNA levels in a total of 18 rats in triplicate experiments $(n=6$ rats per experiment). Representative gel patterns are shown at the top of each graph. $c$, Contralateral; $i$, ipsilateral. For the MVN $(A)$, a mixed-design two-way ANOVA revealed significant effects of survival time $(p<0.005)$, laterality $(p<0.0001)$, and interaction of survival time and laterality $(p<0.0001)$. The ANOVA also showed significant effects for the PrH $(B)$ : survival time $(p=0.011)$, laterality $(p<0.0001)$, and interaction $(p<0.0001)$. Similarly, the ANOVA for the IO $(C)$ indicated significant effects of survival time $(p<0.001)$, laterality $(p<0.0001)$, as well as interaction $(p<0.0005)$. Daggers represent statistical significance compared with control expression levels determined by Duncan's post hoc multiple comparison $(\dagger p<0.05 ; \ddagger p<0.01)$. Asterisks denote a significant difference in BDNF mRNA levels between ipsilateral and contralateral sides revealed by a post hoc paired $t$ test $\left({ }^{*} p<0.05 ;{ }^{*} p<0.01\right)$. The ANOVA indicated that there were no significant effects on time, laterality, and interaction for the control nucleus, XII $(D)$. The BDNF mRNA levels in the sham-operated animals at 3 and $6 \mathrm{hr}$ were also presented on the right side of each graph. 
In the MVN, the BDNF mRNA levels increased in the side ipsilateral to the lesion, whereas no induction was observed in the contralateral side (Fig. 4A). A mixed-design two-way ANOVA on the mRNA expression levels revealed significant effects of survival time $\left(F_{(4,10)}=8.08, p<0.004\right)$, laterality $\left(F_{(1,10)}=78.78\right.$, $p<0.0001)$, and interaction between survival time and laterality $\left(F_{(4,10)}=25.41, p<0.0001\right)$. Three hours after UL, the BDNF mRNA level in the ipsilateral side did not differ from the basal expression level. The BDNF mRNA levels, however, dramatically increased after $6 \mathrm{hr}$ (post hoc Duncan's multiple test; $p<0.01$ compared with control) and were maintained at this level up to 24 hr after UL $(p<0.01)$. When the BDNF mRNA levels were compared between the ipsilateral and contralateral sides, differences were apparent at $6 \mathrm{hr}$ ( post hoc paired $t$ test; $p<0.05$ ) and $24 \mathrm{hr}(p<0.01)$ but not at $3 \mathrm{hr}$ after UL. The BDNF expression levels at $72 \mathrm{hr}$ after UL had decreased somewhat below the basal level and did not differ between the ipsilateral and contralateral sides $(p>0.7)$.

The BDNF induction pattern in the PrH differed from that in the MVN (Fig. 4B); the BDNF mRNA expression levels in the $\mathrm{PrH}$ increased mainly in the contralateral side rather than the ipsilateral side $6 \mathrm{hr}$ after UL (Duncan's multiple test; $p<0.01$ compared with control), and the induction in the contralateral side could be detected by $3 \mathrm{hr}$ after UL $(p<0.05)$. The ANOVA also showed significant effects of survival time $\left(F_{(4,10)}=5.96, p<\right.$ $0.011)$, laterality $\left(F_{(1,10)}=71.90, p<0.0001\right)$, and interaction of survival time and laterality $\left(F_{(4,10)}=20.79, p<0.0001\right)$. The difference in BDNF mRNA levels between the ipsilateral and contralateral sides appeared within $3 \mathrm{hr}$ (paired $t$ test; $p<0.01$ ), reached the maximum level at $6 \mathrm{hr}(p<0.05)$, and was still statistically significant $24 \mathrm{hr}$ after UL $(p<0.05)$. The BDNF mRNA levels then decreased to the basal expression level, and by $72 \mathrm{hr}$ after UL, no difference between the ipsilateral and contralateral sides could be detected $(p>0.3)$.

The BDNF induction was most prominent, among the areas examined, in the IO (Fig. $4 C$ ). The ANOVA revealed significant effects of survival time $\left(F_{(4,10)}=12.09, p<0.0008\right)$, laterality $\left(F_{(1,10)}=119.62, p<0.0001\right)$, as well as interaction of survival time and laterality $\left(F_{(4,10)}=16.85, p<0.0002\right)$. The BDNF mRNA levels in the contralateral IO increased at $3 \mathrm{hr}$ (Duncan's multiple test; $p<0.01)$ and peaked $6 \mathrm{hr}(p<0.01)$ after UL. The induction lasted for at least $24 \mathrm{hr}$ after UL $(p<0.01)$ and returned to the basal level $72 \mathrm{hr}$ after UL. No BDNF induction was observed in the ipsilateral side of the IO. The difference in BDNF mRNA levels between the ipsilateral and contralateral sides appeared at $3 \mathrm{hr}$ (paired $t$ test; $p<0.05$ ), reached the maximum level at $6 \mathrm{hr}(p<0.05)$, and maintained a highly significant level of difference up to $24 \mathrm{hr}$ after UL $(p<0.01)$.

In contrast to the areas described above, the BDNF expression levels did not change over time in a control area, the XII, in either side (Fig. 4D). The ANOVA indicated that there were no significant effects on time $\left(F_{(4,10)}=0.92, p>0.48\right)$, laterality $\left(F_{(1,10)}=0.28, p>0.61\right)$, and interaction $\left(F_{(4,10)}=2.18\right.$, $p>0.14)$ for this area.

We also examined BDNF mRNA changes in sham-operated animals as a control for the effects of the anesthetics and soft tissue injury. In these animals, no BDNF mRNA induction was observed at 3 and $6 \mathrm{hr}$ after the sham operation compared with unoperated controls (Fig. 4). The two-way ANOVA on the mRNA expression levels revealed no significant effects of survival time $\left(\mathrm{MVN}, F_{(2,6)}=1.41, p>0.31 ; \mathrm{PrH}, F_{(2,6)}=0.04, p>0.95\right.$; $\left.\mathrm{IO}, F_{(2,6)}=0.66, p>0.54 ; \mathrm{XII}, F_{(2,6)}=0.75, p>0.51\right)$, laterality
$\left(\mathrm{MVN}, F_{(1,6)}=0.53, p>0.49 ; \mathrm{PrH}, F_{(1,6)}=0.05, p>0.82 ; \mathrm{IO}\right.$, $F_{(1,6)}=0.91, p>0.37$ XII, $\left.F_{(1,6)}=1.19, p>0.31\right)$, and the interaction $\left(\mathrm{MVN}, F_{(2,6)}=0.65, p>0.55\right.$; $\mathrm{PrH}, F_{(2,6)}=1.52, p>$ 0.29 ; IO, $\left.F_{(2,6)}=1.14, p>0.38 ; \mathrm{XII}, F_{(2,6)}=2.55, p>0.15\right)$. These results indicate that the BDNF induction after UL was not related to effects of anesthesia and the unilateral soft tissue injury.

\section{Distribution of BDNF mRNA after unilateral labyrinthectomy}

We next analyzed the BDNF induction by in situ hybridization (Fig. 5). In the MVN and PrH, only a few BDNF mRNA-positive cells were observed in both sides of the control rats (Fig. $5 B$ ). Six hours after UL, the BDNF mRNA-positive cells were detectable in the ipsilateral side of MVN as well as in the contralateral side of the PrH (Fig. 5C). Interestingly, this BDNF mRNA induction appeared to be differentially modulated at the rostral and caudal levels of the MVN and PrH; the ipsilateral BDNF expression in the MVN was prominent in the rostral part (Fig. $5 E, F$ ), whereas the contralateral BDNF expression in the PrH was mostly observed in the caudal part (Fig. $5 G$ ). In these areas, the BDNF induction after UL seemed to be attributable to a small population of cells that expressed BDNF mRNA at high levels.

In the inferior olivary complex of the control rats, only a small number of BDNF mRNA-positive cells were observed in the medial region (that is, the region analyzed by the quantitative RT-PCR), whereas there were many BDNF mRNA-positive cells in the lateral region of this complex (Fig. 5I). Six hours after UL, the number of BDNF mRNA-positive cells in the medial region of the inferior olivary complex greatly increased in the contralateral side but not in the ipsilateral side (Fig. $5 J$ ). BDNF mRNA expression in the lateral region of the complex appeared unchanged. No specific signals were observed in the control sections that were hybridized with the sense-strand BDNF cRNA probes (Fig. $5 K$ ). At high magnification, silver grains were localized around faintly Nissl-stained large nuclei but not around darkly Nissl-stained small nuclei, indicating neuronal expression of BDNF mRNA (Fig. $5 L-N$ ). There were few BDNF mRNApositive cells in the hypoglossal nucleus in the UL-rats as well as in the control rats (data not shown). These results indicate that BDNF mRNA is selectively induced in a subpopulation of neurons in the ipsilateral side of the MVN and the contralateral side of the PrH and the inferior olivary complex, after UL.

\section{c-fos mRNA induction after unilateral labyrinthectomy}

The immediate-early gene c-fos is rapidly induced in neurons in response to changes in synaptic activities (Morgan and Curran, 1991). Several studies have demonstrated induction of c-fos mRNA and c-Fos protein after UL in the MVN, PrH, and IO by in situ hybridization and immunohistochemical staining (Kaufman et al., 1992; Kitahara et al., 1995; Cirelli et al., 1996; Sato et al., 1997). We next quantitatively evaluated the temporal dynamics of c-fos mRNA expression (Fig. 6) to compare them with those of BDNF mRNA expression.

In the MVN (Fig. 6A), the ANOVA revealed significant effects of survival time $\left(F_{(4,10)}=64.84, p<0.0001\right)$, laterality $\left(F_{(1,10)}=\right.$ $15.91, p<0.005)$, and interaction of survival time and laterality $\left(F_{(4,10)}=12.44, p<0.001\right)$. The c-fos mRNA levels increased rapidly in both the ipsilateral and contralateral sides $3 \mathrm{hr}$ after UL (Duncan's multiple test; $p<0.01$ compared with control). The c-fos mRNA level in the ipsilateral side was significantly higher than that in the contralateral side $3 \mathrm{hr}$ (paired $t$ test; $p<0.05$ ), but not $6 \mathrm{hr}$, after UL. The c-fos mRNA levels at 24 and $72 \mathrm{hr}$ after 

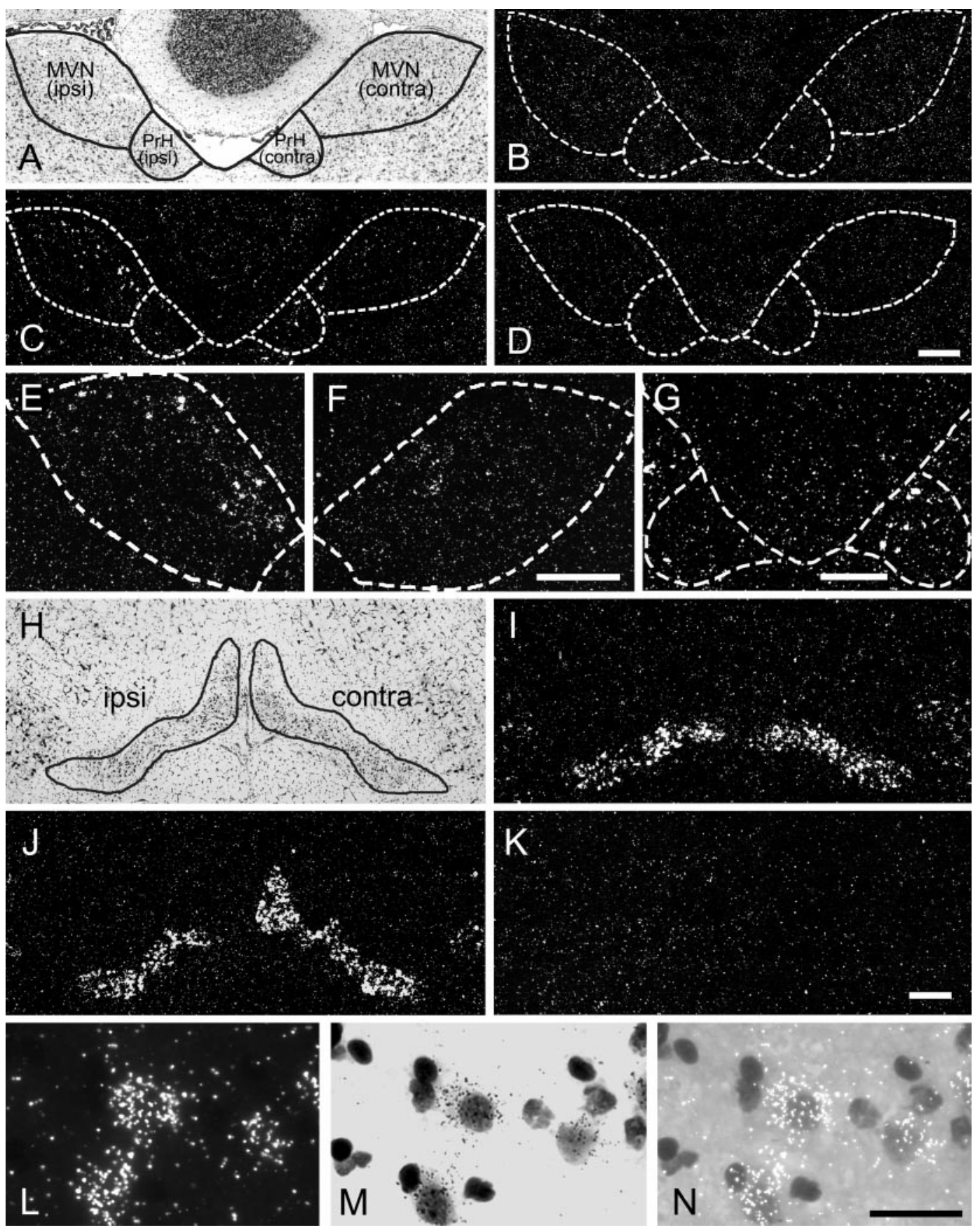

Figure 5. Distribution of BDNF mRNA-positive cells in the brainstem after UL. $A-G$, BDNF mRNA distribution in the MVN and PrH. $A$, A Nissl-stained section of a rat brain $6 \mathrm{hr}$ after UL, indicating the boundaries of the MVN and PrH. The left side of the panel represents the side ipsilateral to the lesion, and the right side indicates the contralateral side. $B$, A section of a control rat brain hybridized with the antisense BDNF probe. Only a few BDNF mRNA-positive cells were observed in the MVN and PrH for both sides. The boundary of the nuclei was defined in an adjacent Nissl-stained section and is overlaid on $B$. $C$, A section of the rat brain $6 \mathrm{hr}$ after UL, hybridized with the antisense BDNF probe. This section is adjacent to the Nissl-stained section shown in $A$. The boundary traced in $A$ is overlaid on $C$. Many BDNF mRNA-positive cells were observed in the ipsilateral MVN and the contralateral PrH. $D$, A control section of the rat brain $6 \mathrm{hr}$ after UL, hybridized with the sense BDNF probe. No specific signal was observed. $E$, $F$, BDNF mRNA-positive cells in the rostral part of the MVN. Shown are the ipsilateral $(E)$ and contralateral $(F)$ MVN taken from the section $120 \mu \mathrm{m}$ rostral to the section shown in $C$. BDNF mRNA-positive cells were most prominent in the rostral part of the ipsilateral MVN. $G$, BDNF mRNA-positive cells in the caudal part of the PrH. The section, $160 \mu \mathrm{m}$ caudal to the section in $C$, showed BDNF mRNA-positive cells in the contralateral PrH. The BDNF expression in the PrH was most obvious in the contralateral side at the caudal level. $H-K$, BDNF mRNA distribution in the inferior olivary complex. $H$, A Nissl-stained section of a rat brain $6 \mathrm{hr}$ after UL, indicating the boundary of the inferior olivary complex. The boundary includes several subdivisions of the inferior olivary complex, although only the medial region of this complex was analyzed in the RT-PCR quantification experiments. I, A section of a control rat brain hybridized with the antisense BDNF probe. BDNF mRNA-positive cells were observed in the lateral region rather than the medial region of the inferior olivary complex. $J$, A section of the rat brain 6 hr after $\mathrm{UL}$, hybridized with the antisense BDNF probe. The section is adjacent to the Nissl-stained section shown in $H$. BDNF mRNA-positive cells were observed in the medial region of the complex in the contralateral side as well as in the lateral region in both sides. $K$, A control section of the rat brain 6 hr after UL, hybridized with the sense BDNF probe. $L-N$, Higher magnification of BDNF mRNA-positive cells in the inferior olivary complex. The cells in the contralateral side of the medial region of the inferior olive are enlarged and shown in dark field $(L)$, bright field $(M)$, and bright field with epi-illumination $(N)$. Silver grains were concentrated around lightly Nissl-stained neuronal nuclei. Scale bars: $A-D, 100 \mu \mathrm{m} ; E, F, 100 \mu \mathrm{m} ; G, 100 \mu \mathrm{m} ; H-K, 100 \mu \mathrm{m} ; L-N, 50 \mu \mathrm{m}$. 

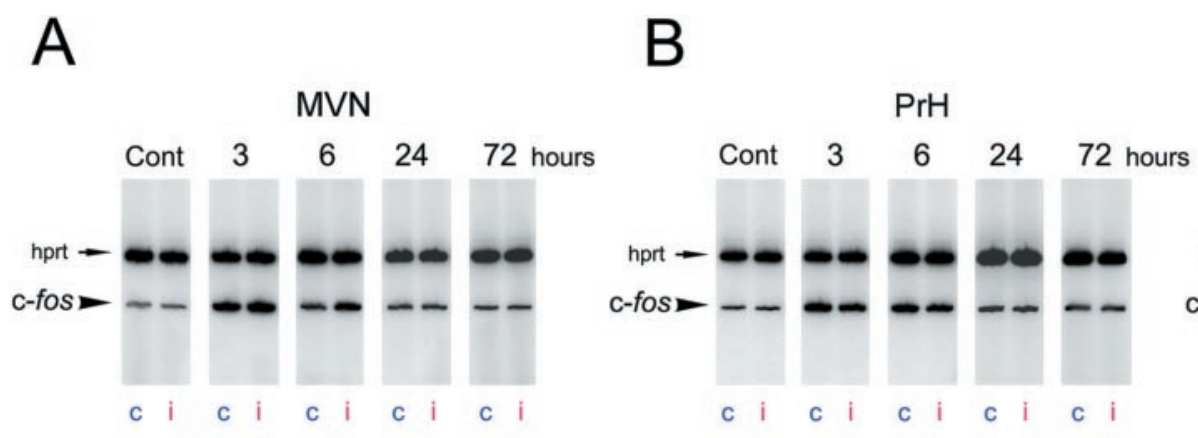

C
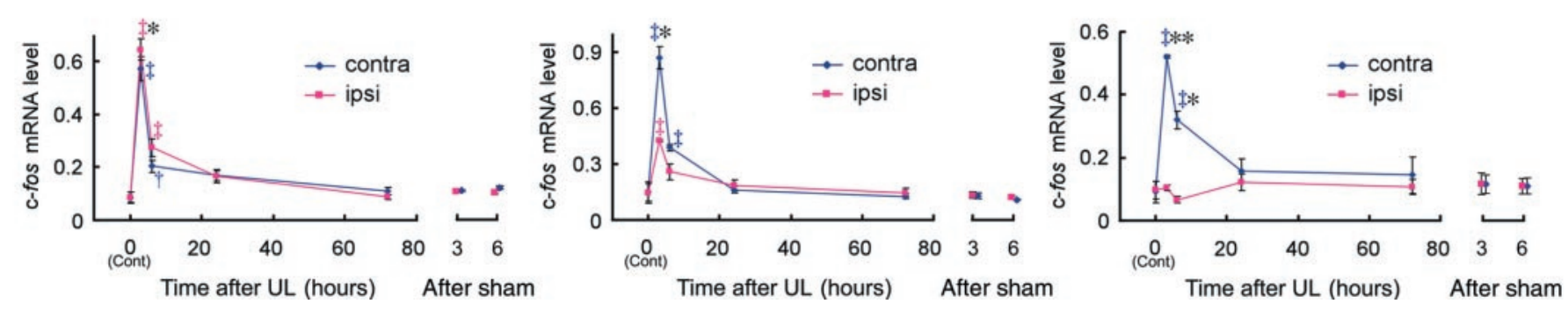

Figure 6. Time course of c-fos mRNA induction after UL. Induction of c-fos mRNA was evaluated by RT-PCR coamplification in the MVN ( $A$ ), PrH $(B)$, and IO $(C)$. The c-fos mRNA levels normalized by the internal standard were plotted as in Figure 4. For the MVN $(A)$, the two-way ANOVA revealed significant effects of survival time $(p<0.0001)$, laterality $(p<0.005)$, and interaction of survival time and laterality $(p<0.001)$. For the PrH $(B)$, the ANOVA showed significant effects of survival time $(p<0.0001)$, laterality $(p<0.0001)$, and interaction $(p<0.0001)$. The ANOVA for the IO $(C)$ also indicated significant effects of survival time $(p<0.005)$, laterality $(p<0.0001)$, as well as interaction $(p<0.0001)$. Daggers represent statistical significance of the difference relative to the mRNA expression level in the control rats (Duncan’s post hoc multiple comparison; $\nmid p<0.05$; $\ddagger p<$ 0.01 ), and asterisks denote a significant difference between the ipsilateral and contralateral sides (a post hoc paired $t$ test; ${ }^{*} p<0.05 ; * * p<0.01$ ). The c-fos mRNA levels in the sham-operated animals at 3 and $6 \mathrm{hr}$ were also presented on the right side of each graph.

UL were no longer different from basal expression levels in both sides. Similar results were obtained from the PrH and IO (Fig. $6 B, C)$. The ANOVA showed significant effects of survival time $\left(F_{(4,10)}=42.41, p<0.0001\right)$, laterality $\left(F_{(1,10)}=64.32, p<\right.$ $0.0001)$, and interaction of survival time and laterality $\left(F_{(4,10)}=\right.$ $42.89, p<0.0001)$ for the $\mathrm{PrH}$, and survival time $\left(F_{(4,10)}=9.02\right.$, $p<0.005)$, laterality $\left(F_{(1,10)}=350.42, p<0.0001\right)$, and the interaction $\left(F_{(4,10)}=105.61, p<0.0001\right)$ for the IO. In both areas, c-fos induction was mainly observed in the contralateral side, and the induction quickly reached maximum levels at $3 \mathrm{hr}$ and decreased to the control levels within $24 \mathrm{hr}$ after UL. These observations are consistent with previously reported expression patterns of c-fos mRNA and its protein product (Kaufman et al., 1992; Kitahara et al., 1995; Cirelli et al., 1996). In the shamoperated animals, c-fos mRNA levels at 3 or 6 hr after the surgery did not differ from the basal expression level. The two-way ANOVA on the mRNA expression levels revealed no significant effects of survival time $\left(\mathrm{MVN}, F_{(2,6)}=1.70, p>0.25 ; \mathrm{PrH}\right.$, $F_{(2,6)}=0.27, p>0.76$; IO, $\left.F_{(2,6)}=0.15, p>0.86\right)$, laterality $\left(\mathrm{MVN}, F_{(1,6)}=3.28, p>0.12 ; \operatorname{PrH}, F_{(1,6)}=0.42, p>0.54\right.$; IO, $\left.F_{(1,6)}=0.62, p>0.45\right)$, and the interaction $\left(\mathrm{MVN}, F_{(2,6)}=1.37\right.$, $p>0.32$; PrH, $\left.F_{(2,6)}=2.84, p>0.13 ; \mathrm{IO}, F_{(2,6)}=0.48, p>0.64\right)$. There was no c-fos induction in the hypoglossal nucleus of the UL rats (data not shown).

We then compared the time courses of BDNF and c-fos induction in the ipsilateral MVN and the contralateral $\mathrm{PrH}$ and $\mathrm{IO}$ (Figs. 4, 6; see also the schematic diagram of Fig. 8). In these three areas, c-fos induction peaked as early as $3 \mathrm{hr}$ after UL and thereafter rapidly declined. In contrast, BDNF mRNA induction had a delayed peak and was much more persistent compared with the c-fos induction. BDNF induction in the MVN was not apparent at $3 \mathrm{hr}$ after UL but occurred dramatically at $6 \mathrm{hr}$ and peaked $24 \mathrm{hr}$ after UL. In the PrH and IO, BDNF mRNA began to increase $3 \mathrm{hr}$ after UL as c-fos mRNA did, but the BDNF induction, which peaked $6 \mathrm{hr}$ after UL, was prolonged up to $24 \mathrm{hr}$ after UL. The two-way ANOVA on induction levels revealed, for these three areas, a significant effect of interaction between factors of survival time and gene $\left(\mathrm{MVN}, F_{(4,10)}=12.44, p<0.001\right.$; $\left.\mathrm{PrH}, F_{(4,10)}=5.40, p<0.02 ; \mathrm{IO}, F_{(4,10)}=9.12, p<0.005\right)$, indicating statistical significance of the difference in the time courses between the BDNF and c-fos induction.

\section{trkB mRNA expression after unilateral labyrinthectomy}

BDNF signals are transmitted into cells via the TrkB tyrosine kinase receptor (Barbacid, 1994). We therefore examined whether trkB mRNA expression levels also changed after UL (Fig. 7A). In contrast to the expression of BDNF and c-fos mRNAs, the trkB mRNA levels did not vary over time after UL in both the ipsilateral and contralateral sides in the MVN, PrH, and IO, as well as in the hypoglossal nucleus (data not shown). The ANOVA for trkB mRNA revealed that there were no significant effects on time, laterality, and the interaction in any of these areas.

Finally, we examined changes in mRNA expression levels after UL for a constitutively expressed "housekeeping" gene, $\alpha$-tubulin, as a control. As expected, the $\alpha$-tubulin mRNA was not induced in either side in any areas (Fig. 7B). The ANOVA for $\alpha$-tubulin mRNA did not show any significant effects on time, laterality, and interaction in any areas examined.

\section{DISCUSSION}

Here we demonstrated the spatiotemporal dynamics of BDNF mRNA induction in the central vestibular system after UL. The present study provides the most quantitative and systematic data regarding gene induction in the brainstem during the early stage of vestibular compensation. We found that the time course of BDNF mRNA induction differed from that of c-fos mRNA in- 
A trkB
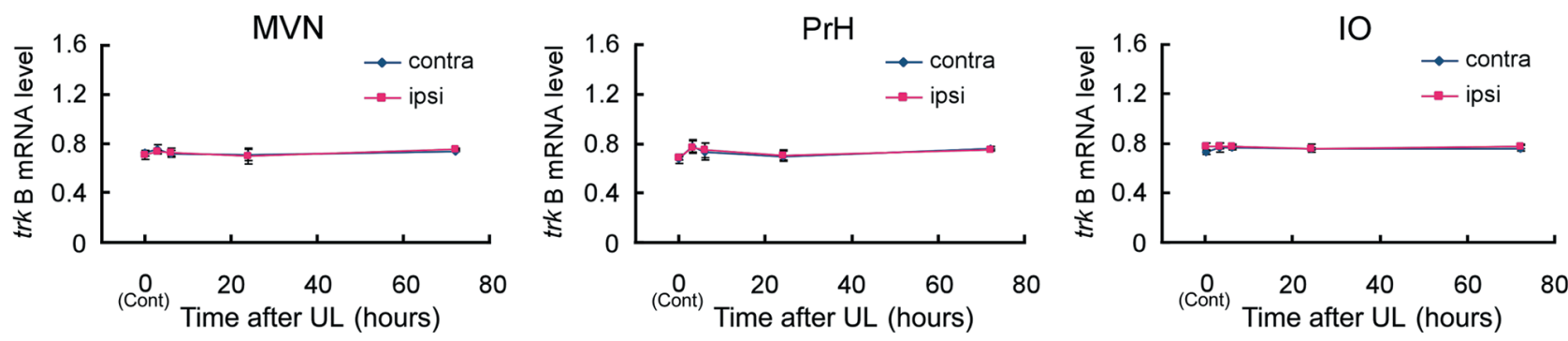

\section{B $\alpha$-tubulin}
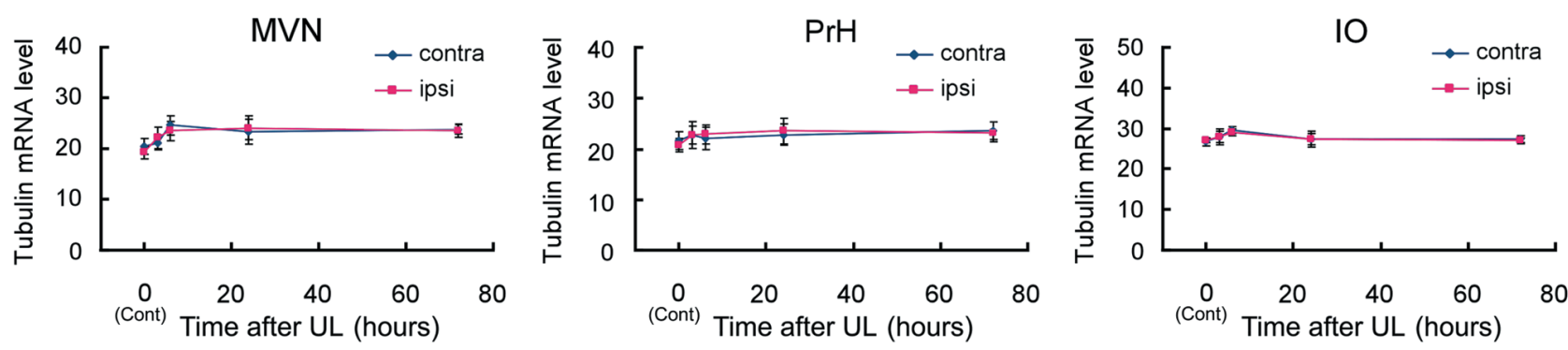

Figure 7. Expression of trkB and $\alpha$-tubulin mRNAs after UL. $A$, trkB mRNA levels in the MVN, PrH, and IO after UL. In all of the areas, no induction was observed for trkB mRNA in both ipsilateral and contralateral sides throughout the early phase of vestibular compensation. $B, \alpha$-tubulin mRNA levels in the MVN, PrH, and IO after UL. The $\alpha$-tubulin mRNA levels also did not change after UL in all areas examined. ANOVA indicated no significant effect on time, laterality, and the interaction in either of these areas for both genes.

duction. The c-fos induction had a sharp peak at $3 \mathrm{hr}$ after UL in the MVN, PrH, and IO, and then the c-fos expression levels decreased to almost basal levels within $24 \mathrm{hr}$ after UL. In contrast, the BDNF mRNA expression levels peaked 6-24 hr after UL. Thus, BDNF induction was relatively slower and more persistent than c-fos induction (Fig. 8). Because most oculomotor and postural disorders after UL, such as spontaneous nystagmus, gradually disappeared by $3 \mathrm{~d}$, molecular events in the early stage of vestibular compensation probably would be most active in the middle of this period, at $\sim 24 \mathrm{hr}$ after UL. The BDNF induction matched well the putative early molecular responses in the central vestibular system. However, the BDNF induction in the brainstem was complete by $72 \mathrm{hr}$ after UL, indicating that BDNF does not contribute to the later stages of vestibular compensation during which motor symptoms in response to head movement (dynamic symptoms) recover gradually over the ensuing weeks or months.

Although both c-fos and BDNF genes are regulated by neuronal activities and are regarded as immediate-early genes in other brain areas (Hughes et al., 1993), the present results indicate that these two genes do not share the same regulation in the MVN, $\mathrm{PrH}$, and IO. Because the c-fos gene encodes a transcription factor, the rapid induction of c-fos, together with other inducible transcription factor genes, possibly activates a subset of genes that modulate synaptic functions during vestibular compensation. BDNF induction after c-fos induction implies that BDNF is one of effector molecules in such a gene subset in the vestibulo-olivary system.

Our quantitative data demonstrated that the mRNA expression levels of a housekeeping gene, $\alpha$-tubulin, were constant over time after UL in all of the areas examined. This observation suggests that the changes in BDNF and c-fos mRNA expression levels are not general phenomena in the brainstem as a consequence of the lesion but are specifically related to the molecular events during vestibular compensation. Our data also demonstrated that the trkB mRNA expression levels did not changed over time after UL. Because the TrkB tyrosine kinase receptor is part of the main stream of the BDNF signaling pathway (Barbacid, 1994), BDNF signaling is likely to be controlled by modulation in the amount of ligand, and not of its receptors, during the early phase of vestibular compensation.

In the present study, we evaluated changes in mRNA expression levels by using the quantitative RT-PCR coamplification method. In this method, the quantity of the target gene was normalized with that of the internal standard gene, and this normalization canceled out variations that occurred during PCR amplification. We have confirmed previously that the quantifiability and reproducibility of this method are comparable with those of RNase protection assays and Northern blotting analysis (Tokuyama et al., 1998, 1999; Okuno et al., 1999). Our PCR-based quantification method thus allows for reliable and efficient analysis of multiple genes when RNA amounts are limited and so is most appropriate for the quantitative evaluation of changes in mRNA expression in the small brainstem regions. Furthermore, we pooled the tissues obtained from several animals for RNA sample preparation. Because the pooling process averaged out animal-to-animal variations in gene expression, we could reliably evaluate the mRNA expression levels and compare them between different animal groups with different survival times.

Our results of the RT-PCR quantification were consistent with those of in situ hybridization. The in situ hybridization analysis gave us complementary information regarding mRNA distribution within a brainstem nucleus and mRNA content in individual cells, although it is difficult to estimate the degree of gene induction in the whole of the nucleus by this method. Our in situ 


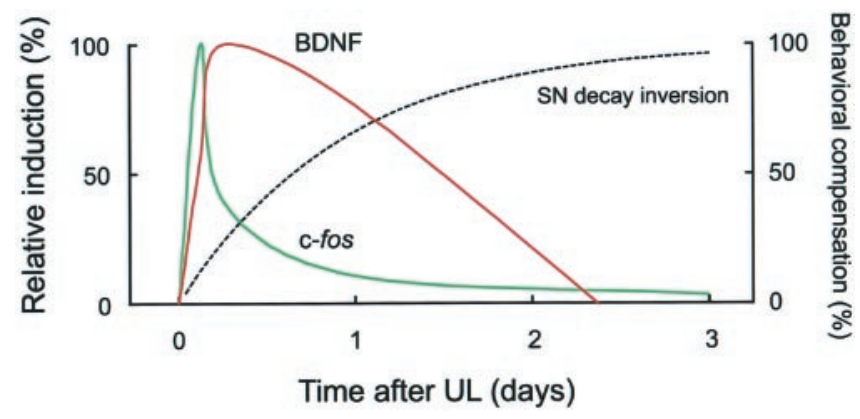

Figure 8. Schematic diagram of the temporal relationship between gene induction and vestibular compensation after UL. The time courses of BDNF and c-fos induction are depicted schematically according to the relative induction levels averaged among the ipsilateral MVN and the contralateral PrH and IO. The relative induction levels were calculated by normalization with the peak values after subtraction of the basal expression levels (left ordinate). The curve for behavioral compensation was drawn based on the inversion of the exponential function fit to the SN recovery, with an asymptote of 100 (right ordinate).

hybridization results suggest that BDNF mRNA expression in the ipsilateral MVN is most apparent at the rostral level. The regional difference in BDNF mRNA induction in the MVN may reflect electrophysiological evidence that neurons in the rostral part of the MVN ipsilateral to the lesion show a sustained increase in excitability after UL (Cameron and Dutia, 1997). In the inferior olivary complex, we observed selective BDNF mRNA induction only in the medial region. The medial region, which mainly contains the $\beta$ nucleus and the dorsal cap, sends climbing fibers to the flocculus, nodulus, and uvula of the cerebellum (Balaban, 1988), and all of these portions of the cerebellum in turn send efferents mostly to the MVN (Langer et al., 1985). Moreover, the medial region of the inferior olivary complex receives prominent inputs from the vestibular nucleus complex, in particular, the MVN, as well as the PrH (Balaban and Beryozkin, 1994). Therefore, among the inferior olivary subnuclei, the medial region is most closely related to vestibular function, and thus it is reasonable to find that BDNF induction was selectively observed in the medial region after UL. Apart from the brainstem, the contribution of the cerebellum in vestibular compensation has also been reported (Goto et al., 1997; Balaban and Romero, 1998). In our study, we did not focus on BDNF induction in the cerebellum because our preliminary experiments showed that the BDNF mRNA expression levels did not change in the flocculus after UL (Y. X. Li and H. Okuno, unpublished observations). Other molecular mechanisms are possibly involved in vestibular compensation in the cerebellum (Goto et al., 1997; Kitahara et al., 1998).

During the developmental stage, BDNF plays a crucial role in the organization of the vestibular system (Jones et al., 1994; Ernfors et al., 1995; Bianchi et al., 1996). However, there is little information available regarding the contribution of BDNF in the vestibular system in adulthood. Recently, some studies suggested roles for BDNF in vestibular compensation. It was reported that bilateral expression of BDNF protein was observed in the lateral vestibular nucleus, but not in the MVN, after UL in guinea pigs (Smith et al., 1998). Because the BDNF protein product can be transported to axonal terminals (Altar and DiStefano, 1998) and the MVN sends both ipsilateral and contralateral projections to the lateral vestibular nucleus (Ito et al., 1985), the difference between the previous report and our present results might indicate the differential distribution of mRNA and protein product of BDNF in the vestibular nucleus. It was also reported recently that the blockage of BDNF expression by an antisense oligonucleotide in the ipsilateral vestibular nucleus had effects on the recovery of some vestibular symptoms after UL (Bolger et al., 1999). Our present results strongly support this behavioral observation. Use of BDNF knock-out mice is probably the most direct means to investigate the roles of BDNF on vestibular compensation. Unfortunately, because homozygous BDNF knock-out (null mutant) mice can survive no longer than a few weeks after birth and also have severe deficits in the vestibular system (Jones et al., 1994; Ernfors et al., 1995; Bianchi et al., 1996), studies on vestibular compensation in the BDNF knock-out mice are not useful at present. One study reported that heterozygous BDNF mutant mice did not show a delay in behavioral recovery after UL, although the compensatory process was not quantitatively evaluated and the sample size was rather small in that study (Gacek and Khetarpal, 1998). Because the heterozygous BDNF mutant mice lack half of their vestibular neurons (Bianchi et al., 1996), the asymmetry of vestibular inputs produced by UL may be relatively weak in these mutant mice compared with that in the wild-type mice. The conditional knockout technique should be used to investigate vestibular compensation in BDNF mutant mice.

The biological and physiological functions of BDNF signaling have been extensively investigated in the CNS (Thoenen, 1995; Bonhoeffer, 1996; Lewin and Barde, 1996; McAllister et al., 1999). Introduction of the BDNF gene leads to maturation of neural circuits and morphological changes in neurons in the neocortex (Hanover et al., 1999; Horch et al., 1999). In addition to the BDNF action on regulating the structure and morphology of neurons, BDNF signaling can rapidly modulate synaptic transmission. The administration of BDNF enhances synaptic efficacy in adult rat hippocampal slices (Kang and Schuman, 1996). Furthermore, it has been proposed recently that BDNF acts as an effective endogenous neuro-excitant (Kafitz et al., 1999). These results indicate that BDNF signaling is directly involved in modulation of the synaptic transmission efficiency, as well as regulation of synaptic connectivity. Together, the spatiotemporalspecific induction of BDNF mRNA shown in the present study highlights the possible contribution of BDNF signaling to the neuronal reorganization in the central vestibular network during vestibular compensation.

\section{REFERENCES}

Altar CA, DiStefano PS (1998) Neurotrophin trafficking by anterograde transport. Trends Neurosci 21:433-437.

Balaban CD (1988) Distribution of inferior olivary projections to the vestibular nuclei of albino rabbits. Neuroscience 24:119-134.

Balaban CD, Beryozkin G (1994) Organization of vestibular nucleus projections to the caudal dorsal cap of Kooy in rabbits. Neuroscience 62:1217-1236.

Balaban CD, Romero GG (1998) A role of climbing fibers in regulation of flocculonodular lobe protein kinase $C$ expression during vestibular compensation. Brain Res 804:253-265.

Barbacid M (1994) The Trk family of neurotrophin receptors. J Neurobiol 25:1386-1403.

Bianchi LM, Conover JC, Fritzsch B, DeChiara T, Lindsay RM, Yancopoulos GD (1996) Degeneration of vestibular neurons in late embryogenesis of both heterozygous and homozygous BDNF null mutant mice. Development 122:1965-1973.

Bolger C, Sansom AJ, Smith PF, Darlington CL (1999) An antisense oligonucleotide to brain-derived neurotrophic factor delays postural compensation following unilateral labyrinthectomy in guinea pig. NeuroReport 10:1485-1488.

Bonhoeffer T (1996) Neurotrophins and activity-dependent development of the neocortex. Curr Opin Neurobiol 6:119-126.

Cameron SA, Dutia MB (1997) Cellular basis of vestibular compensation: changes in intrinsic excitability of MVN neurones. NeuroReport $8: 2595-2599$. 
Cirelli C, Pompeiano M, D’Ascanio P, Arrighi P, Pompeiano O (1996) c-fos expression in the rat brain after unilateral labyrinthectomy and its relation to the uncompensated and compensated stages. Neuroscience 70:515-546.

Darlington CL, Flohr H, Smith PF (1991) Molecular mechanisms of brainstem plasticity. The vestibular compensation model. Mol Neurobiol 5:355-368.

Darlington CL, Lawlor P, Smith PF, Dragunow M (1996) Temporal relationship between the expression of Fos, Jun and Krox-24 in the guinea pig vestibular nuclei during the development of vestibular compensation for unilateral vestibular deafferentation. Brain Res 735:173-176.

Dieringer N (1995) 'Vestibular compensation:' neural plasticity and its relations to functional recovery after labyrinthine lesions in frogs and other vertebrates. Prog Neurobiol 46:97-129.

Ernfors P, Van DW, Loring J, Jaenisch R (1995) Complementary roles of BDNF and NT-3 in vestibular and auditory development. Neuron 14:1153-1164.

Gacek RR, Khetarpal U (1998) Neurotrophin 3, not brain-derived neurotrophic factor or neurotrophin 4 , knockout mice have delay in vestibular compensation after unilateral labyrinthectomy. Laryngoscope 108:671-678.

Galiana HL, Flohr H, Jones GM (1984) A reevaluation of intervestibular nuclear coupling: its role in vestibular compensation. J Neurophysiol 51:242-259.

Gause WC, Adamovicz J (1995) Use of PCR to quantitate relative differences in gene expression. In: PCR primer: a laboratory manual. (Dieffenbach CW, Dveksler GS, eds), pp 293-311. New York: Cold Spring Harbor Laboratory.

Goto MM, Romero GG, Balaban CD (1997) Transient changes in flocculonodular lobe protein kinase $\mathrm{C}$ expression during vestibular compensation. J Neurosci 17:4367-4381.

Hanover JL, Huang ZJ, Tonegawa S, Stryker MP (1999) Brain-derived neurotrophic factor overexpression induces precocious critical period in mouse visual cortex. J Neurosci 19:RC40(1-5).

Hasegawa I, Fukushima T, Ihara T, Miyashita Y (1998) Callosal window between prefrontal cortices: cognitive interaction to retrieve long-term memory. Science 281:814-818.

Hashimoto T, Okuno H, Tokuyama W, Li YX, Miyashita Y (2000) Expression of brain-derived neurotrophic factor, neurotrophin-3 and their receptor messenger RNAs in monkey rhinal cortex. Neuroscience 95:1003-1010.

Horch HW, Kruttgen A, Portbury SD, Katz LC (1999) Destabilization of cortical dendrites and spines by BDNF. Neuron 23:353-364.

Hughes P, Beilharz E, Gluckman P, Dragunow M (1993) Brain-derived neurotrophic factor is induced as an immediate early gene following $N$-methyl-D-aspartate receptor activation. Neuroscience 57:319-328.

Ito J, Matsuoka I, Sasa M, Takaori S (1985) Commissural and ipsilateral internuclear connection of vestibular nuclear complex of the cat. Brain Res 341:73-81.

Ito M (1984) The cerebellum and neural control. New York: Raven Press.

Jones KR, Farinas I, Backus C, Reichardt LF (1994) Targeted disruption of the BDNF gene perturbs brain and sensory neuron development but not motor neuron development. Cell 76:989-999.

Kafitz KW, Rose CR, Thoenen H, Konnerth A (1999) Neurotrophinevoked rapid excitation through TrkB receptors. Nature 401:918-921.

Kang H, Schuman EM (1996) A requirement for local protein synthesis in neurotrophin-induced hippocampal synaptic plasticity. Science 273:1402-1406.

Katoh A, Kitazawa H, Itohara S, Nagao S (1998) Dynamic characteristics and adaptability of mouse vestibulo-ocular and optokinetic response eye movements and the role of the flocculo-olivary system revealed by chemical lesions. Proc Natl Acad Sci USA 95:7705-7710.

Kaufman GD, Anderson JH, Beitz AJ (1992) Brainstem Fos expression following acute unilateral labyrinthectomy in the rat. NeuroReport 3:829-832.

Kitahara T, Takeda N, Saika T, Kubo T, Kiyama H (1995) Effects of MK801 on Fos expression in the rat brainstem after unilateral labyrinthectomy. Brain Res 700:182-190.

Kitahara T, Takeda N, Uno A, Kubo T, Mishina M, Kiyama H (1998) Unilateral labyrinthectomy downregulates glutamate receptor delta-2 expression in the rat vestibulocerebellum. Mol Brain Res 61:170-178.

Langer T, Fuchs AF, Chubb MC, Scudder CA, Lisberger SG (1985) Floccular efferents in the rhesus macaque as revealed by autoradiography and horseradish peroxidase. J Comp Neurol 235:26-37.

Lewin GR, Barde YA (1996) Physiology of the neurotrophins. Annu Rev Neurosci 19:289-317.

McAllister AK, Katz LC, Lo DC (1999) Neurotrophins and synaptic plasticity. Annu Rev Neurosci 22:295-318.

Morgan JI, Curran T (1991) Stimulus-transcription coupling in the nervous system: involvement of the inducible proto-oncogenes fos and jun. Annu Rev Neurosci 14:421-451.

Okuno H, Tokuyama W, Li YX, Hashimoto T, Miyashita Y (1999) Quantitative evaluation of neurotrophin and trk mRNA expression in visual and limbic areas along the occipito-temporo-hippocampal pathway in adult macaque monkeys. J Comp Neurol 408:378-398.

Paxinos G, Carrive P, Wang H, Wang PY (1999) Chemoarchitectonic atlas of the rat brainstem. San Diego: Academic.

Precht W (1979) Vestibular mechanisms. Annu Rev Neurosci 2:265-289.

Ris L, de WC, Serafin M, Vidal PP, Godaux E (1995) Neuronal activity in the ipsilateral vestibular nucleus following unilateral labyrinthectomy in the alert guinea pig. J Neurophysiol 74:2087-2099.

Sato T, Tokuyama W, Miyashita Y, Okuno H (1997) Temporal and spatial dissociation of expression patterns between Zif268 and c-Fos in rat inferior olive during vestibular compensation. NeuroReport 8:1891-1895.

Smith PF, Curthoys IS (1988) Neuronal activity in the ipsilateral medial vestibular nucleus of the guinea pig following unilateral labyrinthectomy. Brain Res 444:308-319.

Smith PF, Darlington CL, Yan Q, Dragunow M (1998) Unilateral vestibular deafferentation induces brain-derived neurotrophic factor (BDNF) protein expression in the guinea pig lateral but not medial vestibular nuclei. J Vestib Res 8:443-447.

Thoenen H (1995) Neurotrophins and neuronal plasticity. Science 270:593-598.

Tokuyama W, Hashimoto T, Li YX, Okuno H, Miyashita Y (1998) Highest trkB mRNA expression in the entorhinal cortex among hippocampal subregions in the adult rat: contrasting pattern with BDNF mRNA expression. Mol Brain Res 62:206-215.

Tokuyama W, Hashimoto T, Li YX, Okuno H, Miyashita Y (1999) Quantification of neurotrophin-3 mRNA in the rat hippocampal subregions using the RT-PCR-based coamplification method. Brain Res Brain Res Protoc 4:407-417.

Tokuyama W, Okuno H, Hashimoto T, Li YX, Miyashita Y (2000) BDNF upregulation during declarative memory formation in monkey inferior temporal cortex. Nat Neurosci 3:1134-1142. 